\title{
Role of Insurance Coverage on Diabetes Preventive Care
}

\author{
Alicestine Ashford ${ }^{1}$, Ji'Lynda Walls ${ }^{1}$, C. Perry Brown ${ }^{1}$, Rima Tawk ${ }^{1 *}$ \\ ${ }^{1}$ Florida A \& M University, College of Pharmacy and Pharmaceutical Sciences, Institute of Public Health, FL, USA
}

*Corresponding Author: rima.tawk@famu.edu

Citation: Ashford, A., Walls, J.L., Brown, C.P. and Tawk, R. (2017). Role of Insurance Coverage on

Diabetes Preventive Care. European Journal of Environment and Public Health, 1(1), 02. https://doi.org/10.20897/ejeph.201702

Published: June 30, 2017

\begin{abstract}
Minorities with diabetes are at an increased risk for low quality care and access to resource utilization, specifically health insurance coverage which often determines access to health care. The purpose of the study was to examine the relationship between insurance coverage and diabetes preventive care after adjusting for patient, physician care, and contextual characteristics. Study used data from the 2010 Medical Expenditure Panel Survey (MEPS). Patients represented a weighted total of 20,741,963 ( $\mathrm{n}=2,182)$. The dependent variables included five measures of the recommended components of diabetes preventive care: receipt of A1C test, retinal eye exam, foot care, blood cholesterol check, and flu vaccination. The independent variables consisted of sociodemographic, physician care, and contextual characteristics. Receipt of each of the diabetes quality and preventive care measures was strongly associated with insurance coverage. Insured individuals were more likely to receive treatment than uninsured. However, the impact of insurance coverage was attenuated after adjusting for individual, physician care, and contextual characteristics. Physician care was the strongest predictor of diabetes preventive care. Our study identified the importance of health insurance coverage on diabetes preventive care. Physician care and contextual factors made a significant impact in receipt of diabetes preventive care.
\end{abstract}

Keywords: insurance coverage, access, diabetes preventive care, racial differences, MEPS

\section{INTRODUCTION}

Diabetes is a debilitating disorder and one that is costly on both the individual and on society. The American Diabetes Association (ADA) in 2016 estimates that there are about eighty-six million Americans who have the distinct possibility of developing the on-set of pre-diabetes and 29.1 million individuals who actually live with the illness.

It is estimated that the total burden displayed by Diabetes as a cultural, social and medical malady is $\$ 245$ billion dollars (American Diabetes Association, 2013). Diabetes affects a large group of the population in the country, but it shares a disproportionate amount of its deleterious burden on the African-American community (Sequist et al., 2006). The role of race in the natural history and care of patients with diabetes has been a concern. AfricanAmericans have a greater prevalence of diabetes than Whites, as well as higher rates of complications, including retinopathy, nephropathy and amputation (Chin et al, 1998). This may lead to poor management of the disease itself, whether it is self-management or that provided by the health care practitioner (Larme et al, 1998). When diabetes goes untreated or undiagnosed for a period of time, it can lead to severe complications including death.

As a leading cause, diabetes is known to be the sixth leading cause of death for Whites and fourth in Blacks and Latinos (Powell et al, 2005). Studies show that inadequate access to medical care contributes to higher rates of adverse health outcomes among some ethnic minorities in the United States. Moreover, Black and other 
minority patients often receive worse technical health care than white Americans (Heisler et al, 2003). These differences in medical care contribute to worse clinical outcomes in minority groups.

Insurance has long been documented as a determinant in access to healthcare services. Under health care reform, low-income uninsured populations will be given the opportunity to improve their access to care, manage unmet health needs, and experience increased use of care/services in some states.

Adults with diabetes are already disproportionately covered under Medicaid. Under health care reform and Medicaid expansion, approximately sixteen million people or more, mostly adults, will gain access to health care. This increase will undoubtedly include many adults with diabetes. With diabetes, many severe complications can occur, including kidney failure, blindness, and heart disease, which are associated with high health care spending. With regular preventive care, self-management and medication use, these complications due to diabetes can be reduced (Garfield \& Domico, 2012).

Garfield \& Domico findings also demonstrate that many of the adults with diabetes that were without insurance reported being in fair or poor health, just as reported by the Medicaid recipients. Conversely, the adults without insurance reported difficulties in accessing services that were needed and many times essential care was delayed which lead to increased complications (Zhang, Huang, Drum, Krichhoff, Schlichting, Schaefer, Heuer, \& Chin, 2009).

To improve the quality of care and the access to care for vulnerable individuals, particularly diabetics, it is necessary to examine how access to insurance influences access to care. Insurance, an enabling access factor plays a big role in diabetic patients receiving proper primary care and preventive care.

There are enormous economic costs associated with diabetes and its secondary complications, including heart disease and stroke, hypertension, blindness, kidney disease, nervous system disease, and amputation. Many of the complications associated with diabetes are preventable. The American Diabetes Association (ADA) recommends that diabetes patients receive a minimum of two A1C tests, foot exam, and one dilated eye exam annually. Thus, it is essential to ensure that these high quality preventive services are provided to the diabetic population.

This study aimed to examine the relationship between insurance coverage and the receipt of diabetes preventive care. We hypothesized that diabetic patients without insurance would be less likely to receive preventive care than those with insurance. We also hypothesized that patient, physician care, and contextual (easy access to care) characteristics play a role in influencing this relationship.

\section{METHODS}

Data for this analysis were obtained from the 2010 Medical Expenditure Panel Survey (MEPS). MEPS is a group of surveys on the financing and use of medical care in the US. It is conducted by the Agency for Healthcare Research and Quality (AHRQ). MEPS collects data through computer-assisted, face-to face interviews. MEPS data include participants' demographic information, the health services that Americans use and how frequently they use them, the cost of these services and how they are paid for, health insurance coverage, household income and employment, the quality of health care.

For this study, the source of data was the Household Component (HC) Full Year consolidated file from 2010 MEPS (2010), which includes respondents' demographic information, diabetes diagnosis, and receipt of diabetes preventive care. This database provides a nationally representative sample of the US civilian, non-institutionalized population of the US. Sampling weights were incorporated to account for the unequal probabilities of selection, and over-sampling. MEPS weights were applied to all estimates.

Individuals 18 years or older, diagnosed with diabetes by a health professional were included in this study. Race was categorized into three groups: Whites, Blacks, and other races. Other races included American Indian/Alaskan native, Asian, native Hawaiian/other Pacific Islander, multiple races reported. The expected primary source of payment was categorized as private insurance, Medicaid, Medicare, and uninsured. Patients with missing patient age or insurance were excluded. The proposal for this study was reviewed and approved by the Institutional Review Board of the Florida A \&M University as an exempt study.

\section{Measures}

Study dependent variables included the five measures of diabetes quality care outcomes: receipt of HbA1c test, retinal eye exam, foot care, blood cholesterol check, and flu vaccination. All the measures of diabetes preventive care were dichotomized. The independent variables consisted of sociodemographic, physician care, and contextual characteristics. The socio-demographic variable included age, gender, race, and insurance coverage. The contextual variable consisted of easy access to getting needed medical care. The physician care variable, included the doctor's explanation of the recommendation guidelines to diabetes preventive care. 
European Journal of Environment and Public Health, 1(1), 02

Table 1. Sample characteristics

\begin{tabular}{lccc}
\hline & Unweighted & Weighted & Percentage \\
\hline $\mathbf{1 8 - 4 4}$ & 315 & $2,779,847$ & 13.4 \\
\hline $\mathbf{4 5 - 6 4}$ & 1,018 & $9,615,746$ & 46.4 \\
\hline $\mathbf{>} \mathbf{6 5}$ & 849 & $8,346,370$ & 40.2 \\
\hline Male & 979 & $10,108,163$ & 48.7 \\
\hline Female & 1,203 & $10,633,799$ & 51.3 \\
\hline White & 1,418 & $15,969,637$ & 77.0 \\
\hline Blacks & 554 & $3,316,798$ & 16.0 \\
\hline Private & 210 & 7.0 \\
\hline Medicare & 670 & $1,455,528$ & 35.4 \\
\hline Medicaid & 754 & $7,338,119$ & 38.7 \\
\hline Uninsured & 493 & $8,021,245$ & 16.9 \\
\hline Cholesterol check Yes & 265 & $3,508,415$ & 9.0 \\
\hline Eye exam Yes & 1,481 & $1,874,183$ & 70.5 \\
\hline Feet care Yes & 1,113 & $14,636,960$ & 55.1 \\
\hline Eye problem Yes & 1,216 & $11,426,890$ & 57.5 \\
\hline Flu vaccination Yes & 406 & $11,939,747$ & 17.0 \\
\hline A1C test Yes & 1,112 & $3,526,803$ & 53.6 \\
\hline Total estimated using & 1,057 & $11,129,069$ & 53.4 \\
\hline
\end{tabular}

a Total is estimated using sampling weights.

\section{Statistical Analysis}

Univariate analysis was first used to examine the association between each predictor variable (sociodemographic, physician care, and contextual characteristics) and the five measures of diabetes quality care. Multiple logistic regression analysis was then used to adjust for individual, physician, and contextual variables when associating insurance coverage with diabetes quality care outcomes. Analyses were performed using PROC FREQ and PROC SURVEYLOGISTIC in SAS Version 9.4 (SAS Institute Inc., Cary, NC).

\section{RESULTS}

The sample population of the adult diabetes patients represented a weighed total of $20,741,963(n=2,182)$. Females $(51.3 \%$ ) were the bulk of the population and 46.4\% were between the ages of $45-64$ of the weighed sample and $86.8 \%$ were above the age of 45 years old. Whites $(77.0 \%)$ were the majority, followed by $16.0 \%$ Blacks, and $7.0 \%$ other race. Patients covered by Medicare constituted $38.7 \%$ of patients, followed by $35.4 \%$ on Private insurance, and $9 \%$ had no health insurance. About 55\% (N=11,426,890) received an eye exam, 53.4\% $(\mathrm{N}=$ $11,070,898)$ reported having an $\mathrm{A} 1 \mathrm{C}$ test, and $70.5 \%(\mathrm{~N}=14,636,960)$ reported having their blood cholesterol checked. Those who received the feet exam made up about $57.5 \%(\mathrm{~N}=11,939,747)$ of the population while those who received flu vaccinations were $53.6 \%(\mathrm{~N}=11,29,069)$ [See Table1].

Univariate comparisons of measures of diabetes preventive care and insurance coverage are shown in Tables 2 through 6. Both unadjusted and adjusted odds ratios found a significant insurance difference in receiving the cholesterol check. Compared with uninsured patients, patients with private insurance had the highest odds of receiving cholesterol check $(\mathrm{OR}=3.012)$ followed by patient receiving Medicare, then Medicaid patients in the unadjusted model. After adjusting for the other characteristics, the multivariate odds ratios were $(2.427,1.654$, 1.519) for private insurance, Medicaid, and Medicare respectively. Multivariate analysis of insurance coverage was statistically significant among the five measures of diabetes preventive care except for Medicare where it failed to reach statistical significance with the foot care model (AOR $=1.270 ; 95 \%$ CI $0.793-2.035)$. Another instance where insurance difference was not captured was in the A1c exam model where both Medicare and Medicaid failed to reach statistical significance $(\mathrm{AOR}=1.316 ; 95 \% \mathrm{CI} 0.860-2.015, \mathrm{AOR}=0.975 ; 95 \% \mathrm{CI} 0.666-1.427$ ) respectively.

The association of each insurance category with the five measures of diabetes preventive care is reported below. After accounting for other characteristics, patients with private insurance had the highest odds ratios of receipt of cholesterol check, eye exam, and A1c test. Whereas, patients receiving Medicare coverage had the highest likelihood of receiving the flu vaccination, and patients receiving Medicaid coverage were more likely to receive foot care. Patients with private insurance had the strongest association with receipt of cholesterol check when compared to other measures of diabetes preventive care. 
Table 2. Logistic multiple models predicting the receipt of cholesterol check*

\begin{tabular}{|c|c|c|}
\hline & Univariate Odds Ratio $(95 \% \mathrm{CI})$ & Multivariate Odds Ratio $(95 \% \mathrm{CI})$ \\
\hline Private & $3.012(2,138,4.245)$ & $2.427(1.604,3.672)$ \\
\hline Medicare & $2.734(1.952,3.830)$ & $1.654(1.077,2.541)$ \\
\hline Medicaid & $2.188(1.537,3.114)$ & $1.519(0.943,2.448)$ \\
\hline Uninsured & 1.000 & 1.000 \\
\hline Blacks & $0.627(0.495,0.796)$ & $0.719(0.548,0.944)$ \\
\hline Other race & $0.752(0.503,1.125) \mathbf{N S}$ & $0.820(0.528,1.274) \mathbf{N S}$ \\
\hline Whites & 1.000 & 1.000 \\
\hline Female & $1.134(0.900,1.428) \mathbf{N S}$ & $1.188(0.935,1.508) \mathbf{N S}$ \\
\hline Male & 1.000 & 1.000 \\
\hline $18-44$ & 1.000 & 1.000 \\
\hline $45-64$ & $1.511(1.144,1995)$ & $1.383(0.977,1.958)$ \\
\hline$>=65$ & $1.726(1.281,2.325)$ & $1.858(1.213,2.845)$ \\
\hline \multicolumn{3}{|l|}{ Ease of care } \\
\hline Never & 1.000 & 1.000 \\
\hline Sometimes & $2.435(1.409,4.210)$ & $1.643(0.921,2.928)$ \\
\hline Usually & $3.208(2.293,4.488)$ & $1.729(1.193,2.507)$ \\
\hline Always & $3.775(2.851,5.000)$ & $1.832(1.321,2.539)$ \\
\hline \multicolumn{3}{|c|}{ Explanation of doctor } \\
\hline Never & 1.000 & 1.000 \\
\hline Sometimes & $3.640(2.248,5.895)$ & $2.333(1.342,4.055)$ \\
\hline Usually & $5.897(4.090,8.502)$ & $3.649(2.398,5.551)$ \\
\hline Always & $5.466(4.075,7.332)$ & $3.278(2.325,4.621)$ \\
\hline
\end{tabular}

* Bold values under the "Odds Ratio" column indicate reference category for each variable.

Table 3. Logistic multiple models predicting the receipt of eye exam*

\begin{tabular}{|c|c|c|}
\hline & Univariate Odds Ratio (95\% CI) & Multivariate Odds Ratio $(95 \% \mathrm{CI})$ \\
\hline Private & $2.763(1.800,4.243)$ & $2.271(1.442,3.577)$ \\
\hline Medicare & $3.266(2.175,4.903)$ & $1.989(1.246,3.175)$ \\
\hline Medicaid & $2.266(1.500,3.425)$ & $1.760(1.143,2.710)$ \\
\hline Uninsured & 1.000 & 1.000 \\
\hline Blacks & $0.737(0.593,0.917)$ & $0.860(0.690,1.071) \mathbf{N S}$ \\
\hline Other race & $0.639(0.450,0.906)$ & $0.695(0.456,1.058)$ \\
\hline Whites & 1.000 & 1.000 \\
\hline Female & $1.085(0.888,1.326) \mathrm{NS}$ & $1.123(0.904,1.395) \mathbf{N S}$ \\
\hline Males & 1.000 & 1.000 \\
\hline $18-44$ & 1.000 & 1.000 \\
\hline $45-64$ & $1.409(1.026,1.936)$ & $1.280(0.912,1.795) \mathbf{N S}$ \\
\hline$>=65$ & $1.906(1.424,2.551)$ & $1.671(1.167,2.392)$ \\
\hline \multicolumn{3}{|l|}{ Ease of care } \\
\hline Never & 1.000 & 1.000 \\
\hline Sometimes & $1.427(0.934,2.180)$ & $0.952(0.592,1.530) \mathbf{N S}$ \\
\hline Usually & $2.389(1.733,3.293)$ & $1.365(0.951,1.959)$ \\
\hline Always & $2.651(2.045,3.437)$ & $1.383(0.989,1.933)$ \\
\hline \multicolumn{3}{|c|}{ Explanation of doctor } \\
\hline Never & 1.000 & 1.000 \\
\hline Sometimes & $3.394(2.042,5.642)$ & $2.760(1.551,4.910)$ \\
\hline Usually & $4.529(3.295,6.225)$ & $3.423(2.283,5.130)$ \\
\hline Always & $4.205(3.099,5.706)$ & $3.092(2.089,4.578)$ \\
\hline
\end{tabular}

* Bold values under the "Odds Ratio" column indicate reference category for each variable. 
Table 4. Logistic multiple models predicting the receipt of foot exam*.

\begin{tabular}{|c|c|c|}
\hline & Univariate Odds Ratio (95\% CI) & Multivariate Odds Ratio $(95 \% \mathrm{CI})$ \\
\hline Private & $1.795(1.253,2.572)$ & $1.419(0.953,2.112)$ \\
\hline Medicare & $1.833(1.303,2.579)$ & $1.270(0.793,2.035) \mathbf{N S}$ \\
\hline Medicaid & $1.726(1.183,2.518)$ & $1.469(0.957,2.255)$ \\
\hline Uninsured & 1.000 & 1.000 \\
\hline Blacks & $0.734(0.577,0.933)$ & $0.818(0.628,1.064) \mathbf{N S}$ \\
\hline Other race & $1.134(0.793,1.622) \mathrm{NS}$ & $1.250(0.850,1.840) \mathbf{N S}$ \\
\hline Whites & 1.000 & 1.000 \\
\hline Female & $0.911(0.725,1.145) \mathbf{N S}$ & $0.891(0.698,1.138) \mathbf{N S}$ \\
\hline \multicolumn{3}{|l|}{ Males } \\
\hline $18-44$ & 1.000 & 1.000 \\
\hline $45-64$ & $1.563(1.111,2.199)$ & $1.503(1.019,2.216)$ \\
\hline$>=65$ & $1.653(1.191,2.293)$ & $1.604(1.010,2.549)$ \\
\hline \multicolumn{3}{|l|}{ Ease of care } \\
\hline Never & 1.000 & 1.000 \\
\hline Sometimes & $1.564(0.999,2.450)$ & $1.129(0.682,1.868) \mathbf{N S}$ \\
\hline Usually & $2.145(1.477,3.113$ & $1.272(0.843,1.918) \mathbf{N S}$ \\
\hline Always & $2.401(1.837,3.138)$ & $1.223(0.895,1.671) \mathbf{N S}$ \\
\hline \multicolumn{3}{|c|}{ Explanation of doctor } \\
\hline Never & 1.000 & 1.000 \\
\hline Sometimes & $2.161(1.344,3.477)$ & $1.768(1.069,2.925)$ \\
\hline Usually & $3.862(2.718,5.487)$ & $3.165(2.128,4.709)$ \\
\hline Always & $4.312(3.135,5.931)$ & $3.557(2.456,5.153)$ \\
\hline
\end{tabular}

* Bold values under the "Odds Ratio" column indicate reference category for each variable.

Table 5. Logistic multiple models predicting the receipt of flu vaccination*.

\begin{tabular}{|c|c|c|}
\hline & Univariate Odds Ratio (95\% CI) & Multivariate Odds Ratio $(95 \% \mathrm{CI})$ \\
\hline Private & $2.402(1.654,3.490)$ & $2.007(1.353,2.977)$ \\
\hline Medicare & $3.770(2.583,5.503)$ & $2.287(1.363,3.837)$ \\
\hline Medicaid & $2.466(1.734,3.508)$ & $1.947(1.286,2.947)$ \\
\hline Uninsured & 1.000 & 1.000 \\
\hline Blacks & $0.642(0.500,0.824)$ & $0.725(0.560,0.939)$ \\
\hline Other race & $0.881(0.609,1.273) \mathbf{N S}$ & $1.012(0.669,1.530) \mathbf{N S}$ \\
\hline White & 1.000 & 1.000 \\
\hline Female & $1.132(0.923,1.389) \mathbf{N S}$ & $1.176(0.948,1.460) \mathbf{N S}$ \\
\hline Male & 1.000 & 1.000 \\
\hline $18-44$ & 1.000 & 1.000 \\
\hline $45-64$ & $1.535(1.100,2.142)$ & $1.430(0.991,2.065)$ \\
\hline$>=65$ & $2.513(1.785,3.539)$ & $1.938(1.233,3.046)$ \\
\hline \multicolumn{3}{|l|}{ Ease of care } \\
\hline Never & 1.000 & 1.000 \\
\hline Sometimes & $1.675(1.063,2.641$ & $1.137(0.666,1.941) \mathbf{N S}$ \\
\hline Usually & $2.359(1.708,3.259)$ & $1.376(0.940,2.014) \mathbf{N S}$ \\
\hline Always & $2.431(1.896,3.117)$ & $1.319(0.989,1.760)$ \\
\hline \multicolumn{3}{|c|}{ Explanation of doctor } \\
\hline Never & 1.000 & 1.000 \\
\hline Sometimes & $3.923(2.459,6.258)$ & $3.179(1.843,5.484)$ \\
\hline Usually & $4.131(2.889,5.908)$ & $3.115(1.981,4.896)$ \\
\hline Always & $3.714(2.672,5.163)$ & $2.822(1.896,4.200)$ \\
\hline
\end{tabular}

* Bold values under the "Odds Ratio" column indicate reference category for each variable. 
Table 6. Logistic multiple models predicting the receipt of A1C test*.

\begin{tabular}{|c|c|c|}
\hline & Univariate Odds Ratio (95\% CI) & Multivariate Odds Ratio $(95 \% \mathrm{CI})$ \\
\hline Private & $2.039(1.424,2.921)$ & $1.634(1.125,2.371)$ \\
\hline Medicare & $1.378(0.947,2.006)$ & $1.316(0.860,2.015) \mathbf{N S}$ \\
\hline Medicaid & $1.099(0.771,1.567) \mathbf{N S}$ & $0.975(0.666,1.427) \mathbf{N S}$ \\
\hline Uninsured & 1.000 & 1.000 \\
\hline Blacks & $0.557(0.438,0.709)$ & $0.603(0.467,0.778)$ \\
\hline Other race & $0.659(0.464,0.935)$ & $0.678(0.470,0.977)$ \\
\hline White & 1.000 & 1.000 \\
\hline Female & $1.104(0.922,1.322) \mathbf{N S}$ & $1.188(0.986,1.432)$ \\
\hline Male & 1.000 & 1.000 \\
\hline $18-44$ & 1.000 & 1.000 \\
\hline $45-64$ & $1.100(0.797,1.518) \mathbf{N S}$ & $0.934(0.651,1.339) \mathbf{N S}$ \\
\hline$>=65$ & $0.828(0.593,1.155) \mathbf{N S}$ & $0.717(0.470,1.093) \mathbf{N S}$ \\
\hline \multicolumn{3}{|l|}{ Ease of care } \\
\hline Never & 1.000 & 1.000 \\
\hline Sometimes & $1.706(1.049,2.776)$ & $1.164(0.673,2.012) \mathbf{N S}$ \\
\hline Usually & $2.424(1.753,3.353)$ & $1.557(1.073,2.260)$ \\
\hline Always & $2.648(2.037,3.443)$ & $1.627(1.187,2.231)$ \\
\hline \multicolumn{3}{|c|}{ Explanation of doctor } \\
\hline Never & 1.000 & 1.000 \\
\hline Sometimes & $3.039(1.893,4.877)$ & $2.315(1.360,3.942)$ \\
\hline Usually & $3.459(2.484,4.818)$ & $2.368(1.596,3.514)$ \\
\hline Always & $3.535(2.509,4.979)$ & $2.429(1.615,3.654)$ \\
\hline
\end{tabular}

* Bold values under the "Odds Ratio" column indicate reference category for each variable.

Considering all other predictor variables, the physician care related variable consistently held the highest odds ratio among all five measures of diabetes preventive care (AOR $=2.315-3.649)$. Ease of care and age in particular for those aged 65 years old and above were also strong predictors of diabetes preventive care. Race was strongly associated with receipt of A1c test models for Blacks, and other races as compared to whites (AOR= $0.603 ; 0.678)$ respectively. Our study failed to capture statistical significant racial differences for both groups with respect to the eye exam, and the foot exam models. However, in both unadjusted eye and foot exam models, the racial difference was captured for the eye exam for both groups, but only for Blacks in the feet exam model. With respect to the cholesterol check model and flu vaccination models, the racial differences was captured for Blacks only but failed to reach statistical significance for other races.

\section{DISCUSSION}

To the best of our knowledge, our study is one of the first to examine the relationship between insurance coverage and five of the recommended components of diabetes preventive care after adjusting for patient, physician care related variable, and contextual characteristics. Receipt of each of the diabetes quality care measures was strongly associated with insurance coverage. Insured individuals were more likely to receive treatment than uninsured. However, the impact of insurance coverage was attenuated after adjusting for individual, physician care, and contextual characteristics. Physician care was the strongest predictor of diabetes preventive care. The ease of care was also strongly associated with diabetes quality care.

With regards to race, our study failed to capture racial difference in terms of diabetic foot, and eye exams even though the disparities have been reported in the literature (Pu et al., 2013). However, our study captured racial difference in receiving A1c tests. This quality care outcome result was in agreement with another study. (Pu et al., 2013).

To reduce disparities in diabetes preventive care, insurance has a major role to play. Patients who are uninsured, and in the low-income population require the attention of providers, administrators, and legislators to eliminate disparities and reduce costs. The literature indicates that low-income diabetes patients are less likely to receive preventive care than their wealthy counterparts (Pu et al., 2013).

Our analyses may have been limited by the use of administrative data, which lack clinical detail compared with record reviews. The MEPS data set has an over representation to minorities in their sample. Another limitation 
of the study was that that all information was self-reported. In addition, respondents' burden, recall bias, over reporting or under reporting due to social norms could be listed as other limitations.

The results from this large representative sample of diabetic patients may be of value to health care administrators, health care professionals in helping to profile adults at risk for diabetes. These findings have important implications for diabetes preventive health education and shed light on the role that access to patientcentered care, and physician- patient relationships play in the health outcomes of diabetics. In addition, the findings may be valuable to inform policy makers regarding the importance of access barriers and their impact on health disparities.

\section{CONCLUSION}

Our study identified the importance of health insurance coverage on diabetes preventive care. Physician care and contextual factors made a significant impact in receipt of diabetes preventive care. With added coverage that comes with ACA, will the uninsured population gain similar health status as the insured population?

\section{REFERENCES}

American Diabetes Association (2013). Economic Costs of Diabetes in the U.S. in 2012. Diabetes Care, 36(4), pp. 1033-1046.

Chin, M.H., Zhang, J.X. and Merrell, K. (1998). Diabetes in the African American Medicare Population: Morbidity, Quality of Care, and Resource Utilization. Diabetes Care, 21(7), pp. 1090-1095.

Fields, D., Leshen, E. and Patel, K. (2010). Analysis \& commentary. Driving quality gains and cost savings through adoption of medical homes. Health Affairs, 29(5), pp. 819-26.

Garfield, R.L. and Damico, A. (2012). Medicaid expansion under health reform may increase Service use and improve access for low-income adults with diabetes. Health Affairs, 31(1), pp. 159-167.

Ginsburg, P.B., Maxfield, M., O’Malley, A.S., Peikes, D. and Pham, H.H. (2008). Making Medical Homes Work: Moving from Concept to Practice. Policy Perspective No. 1 Center for Studying Health System Change.

Heisler, M., Smith, D., Hayward, R.A., Krein, S.L. and Kerr, E.E. (2003). Racial Disparities in Diabetes Care Processes, Outcomes, and Treatment Intensity. Medicare Care, 41(11), pp. 1221-1232.

Iglehart, J.K. (2012). Expanding eligibility, cutting costs- A medicaid update. The New England Journal of Medicine, 366(2), pp. 105-107.

Larme, A.C. and Pugh, J.A. (1998). Attitudes of primary care providers towards diabetes: Barriers to guideline implementation. Diabetes care, 21(9), pp. 1391-1396.

$\mathrm{Pu}, \mathrm{J}$. and Chewning, B. (2013). Racial differences in diabetes preventive care. Research in Social and Administrative Pharmacy, 9(6), pp. 790-796.

Ratanawongsa, N., Bhandari, V.K., Handley, M., Rundall, T., Hammer, H. and Schillinger, D. (2012). Primary care provider perceptions of the effectiveness of two self-management support programs for vulnerable patients with diabetes. Journal of Diabetes Science and Technology, 6(1), pp. 116-124.

Robinson, J., Callister, L.C., Berry, J. and Dearing, K.A. (2008). Patient Centered Care and Adherence: Definitions and Applications to Improve Outcomes. Journal of American Association of Nurse Practitioners, 20(2), pp. 600-607.

Rosenthal, M.B., Sinaiko, A.D., Eastman, D., Chapman, B. and Partridge, G. (2015). Impact of the Rochester medical home initiative on primary care practices, quality, utilization, and costs. Medical Care, 53(11), pp. 967973.

Shi, L., Lebrun, L. and Tsai, J. (2010). Access to medical care, dental care, and prescription drugs: the role of race/ethnicity, health insurance, and income. Southern Medical Journal, 103(6), pp. 509-516.

Zhang, J.X., Huang, E.S., Drum, M.L., Kirchhoff, A.C., Schlichting, J.A., Schaefeer, C.T., Heuer, L.J. and Chin, M.H. (2009). Insurance status and quality of diabetes in community health centers. American Journal of Public Health, 99(4), pp. 742-747. 